\title{
Induced breeding practices of the fish hatcheries in the north-western region of Bangladesh
}

\begin{abstract}
This investigational study was conducted on the fish hatcheries of the north-western region of Bangladesh to know about their induced breeding practices. It was observed that 6 native species viz. Rui(Labeorohita), Catla (Catlacatla), Mrigel (Cirrhinus cirrhosus), Calibaush (Labeo calbasu), Bata (Labeobata) and Gonia (Labeo gonius), 2 catfishes such as Shing (Heteronopneustes fossilis) and Magur (Clarius batrachus) and 7 exotic species viz. Silver carp (Hypopthalmicthys molitrix), Bighead carp (Aristichthysnobilis), Grass carp (Ctenopharyngodon idella), Common carp (Cyprinuscarpio), Black carp (Mylopharyngodon piceum), Thai pangus (Pangasius sutchi), Thai puti or raj puti (Barbonymus gonionotus) were used in the surveyed hatcheries for induced breeding purpose. Three types of inducing agents viz. PG (Pituitary Gland), HCG (Human Chorionic Gonadotropin) and GnRHa (Gonadotropin Releasing Hormone analogues) were used for induced breeding. The rate of the $1 \mathrm{st}$ dose of injection of PG varied from 1 to $4 \mathrm{mg} / \mathrm{kg}$ body weight, $\mathrm{HCG}$ varied from 100 to $200 \mathrm{IU} / \mathrm{Kg}$ body weight and GnRHa (only one dose) varied from 0.10 to $0.90 \mathrm{ml} / \mathrm{kg}$ body weight. The rate of the $2 \mathrm{nd}$ dose of injection of $\mathrm{PG}$ varied from 4 to $10 \mathrm{mg} / \mathrm{kg}$ body weight. Finally, the incubation period and hatching rates in different fish species varied from 10 to 70 hours and 55 to $85 \%$ respectively.
\end{abstract}

Keywords: Induced breeding, Inducing agents, PG, HCG, GnRHa, Brood fishes, Hatching
Volume 2 Issue 6 - 2015

Naima Aktar, Nazrul Islam M
Department of Zoology, University of Rajshahi, Bangladesh

Correspondence: Naima Aktar, Department of Zoology, University of Rajshahi, Faculty of Life and Earth Science, Rajshahi 6205, Bangladesh, Email naimaru85@gmail.com

Received: August 19,2015 | Published: October 14, 2015
Abbreviations: PG, Pituitary Gland; HCG, Human Chorionic Gonadotropin; GnRHa, Gonadotropin Releasing Hormone Analogues; GDP, Gross Domestic Product; DoF, Department of Fisheries; UN's, United Nation's; FAO, Food and Agricultural Organization; SD, Standard Deviation

\section{Introduction}

Bangladesh is blessed and enriched with vast water resources, which show a wide range of variation in nature. As a consequence, natural fisheries resources are scattered all over the country. According to DoF, 2014, the contribution of fisheries sector to the national GDP (gross domestic product) is $4.37 \%$ and $2.01 \%$ to the export earning of Bangladesh. Bangladesh presently stands fourth in fresh water aquaculture according to this year's (2014) report of UN's Food and Agricultural Organization FAO. ${ }^{1}$ Nowadays, due to the degradation of the ecological balance, changing catchments, construction of drainage structures and flood control, siltation, soil erosion, washing of industrial pollutants and agrochemicals, the capture fisheries in open waters of Bangladesh is under great danger. In 2012-13 inland capture fisheries contributed only to $28.2 \%$ of the total fish production. For that reason, aquaculture has been developed in this country, which mainly depends on fish hatcheries, a place for artificial breading, hatching and rearing through the early life stages of fish Coche \& Crespi. $^{2}$

By fish hatchery we refer to a place where brood fish are stocked in growth ponds, eggs are fertilized and hatched up to fingerlings in artificial conditions by the process of induced breeding. According to Bhuiyan et al., ${ }^{3}$ induced breeding is a process where the fish, which do not breed in stagnant water bodies, will do so under the influence of some stimulants or hormones injected in their bodies. Induced breeding, also called hypophysation or artificial propagation, has now overcome the problems of fish seeds production for the particular fish which do not breed in captivity. In this process, some stimulating agents or hormones are injected into the ripe brood fish and hence the stimulation promotes the releasing of eggs and milk from these ripe breeders timely in captive condition.

Induced breeding is done for artificial propagation of fish and it has been established as a dependable source of fish seeds since the mid-1960s in fish hatcheries for production of fry or fingerlings which contributes significantly to the overall aquaculture production of Bangladesh Rahman et al. ${ }^{4}$ Along with the problem of significant reduction of stocks of natural fisheries, there is an increasing need to develop artificial reproduction technology for high commercially valuable species in order to improve their reproductive potential and consequently the production of fingerlings for fish culture and restocking. Spawning induction in freshwater fish is usually performed using the hypophysation method Arantes et al. ${ }^{5}$

\section{Materials and methods}

\section{Study area and duration}

The study deals with fish hatcheries of north-western region of Bangladesh (Figure 1). The north-western region of Bangladesh consists of two divisions, named Rajshahi and Rangpur. Rajshahi division is in the north western part of Bangladesh. The famous Padma River borders Rajshahi division on the south and another famous river, Jamuna, lies across the eastern border. In the north and west, Rajshahi division shares a border with India. Rajshahi division is located in between $23^{\circ} 48 \phi$ and $25^{\circ} 16 \phi$ north latitudes and in between $88^{\circ} 01 \phi$ and $89^{\circ} 48 \notin$ east longitudes. On the other hand, Rangpur division lies in the northwestern corner of Bangladesh, a few miles south from the Teesta River. Rangpur division is located in between $25^{\circ} 20 \phi$ and $26^{\circ} 37 \phi$ north latitudes and in between $88^{\circ} 50 \phi$ and $89^{\circ} 53 \phi$ east longitudes. The study areas are shown in the location map Figure 1.

\section{Data collection}

For data collection, the selection of sample size was one of the crucial aspects for the study. Therefore, a reasonable sample size and 
a schedule for survey were considered for data collection on induced breeding of fish hatcheries in the North-western region of Bangladesh. The primary data were collected by interview and survey, whereas secondary data were collected from divisional and district fishery offices.

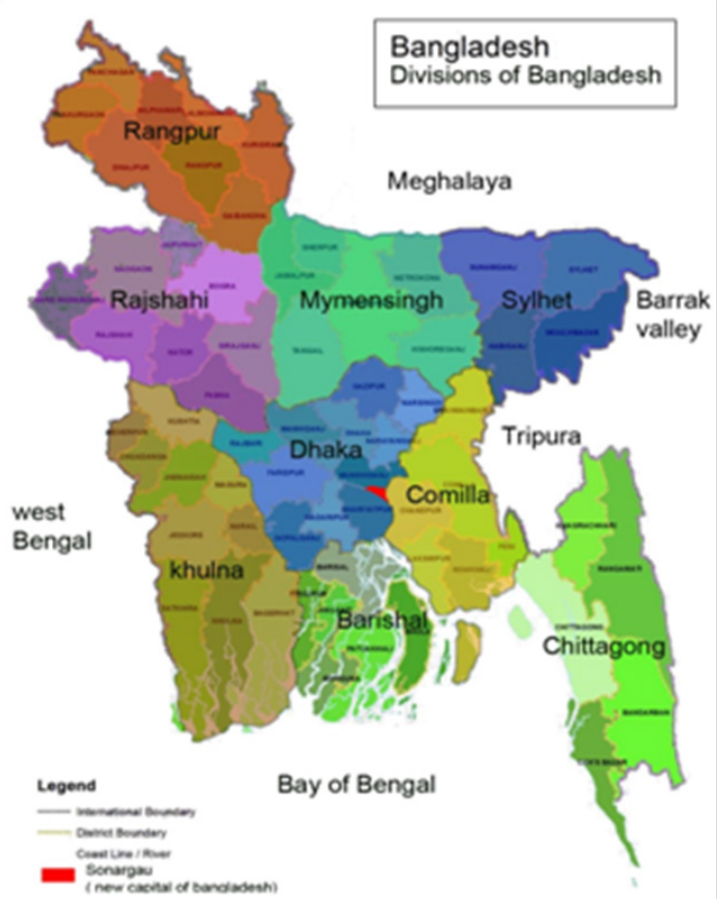

Figure I Map-I showing the locations of the study areas of Rajshahi and Rangpur division of Bangladesh.

\section{Data processing and analysis}

The collected data were cheeked and cross-checked for reliability Table I Doses of Ovupin $®$ for the induced breeding of the fish and accuracy. All the collected data were carefully summarized and scrutinized and finally a number of relevant tables were prepared and analyzed by MS Excel.

\section{Results and discussions}

\section{Brood fishes selection for induced breeding}

According to Hasan \& Ahmed, ${ }^{6}$ three Indian major carps (rui, catla and mrigel) and three exotic carps (silver carp, grass carp and common carp) were the dominant fish species used as brood fish in most hatcheries of Bangladesh. Bhuiyan et al. ${ }^{7}$ stated that healthy brood fish selection is important for induced spawning of Labeo rohita. The present results corroborate the previous results of the mentioned scientists (Table 1).

Table 2 presents, species wise, the minimum and maximum length, age and weight of the brood fish and minimum-maximum stocking density of the brood fish which are used in the hatcheries under study.

\section{Inducing agents and hormonal dose selection}

In the studied hatcheries, three types of inducing agents such as pituitary gland (PG), human chorionic Gonadotropin (HCG) and Gonadotropin Releasing Hormone analogues (GnRHa) under the trade name Ovupin (100 mg Domperidone + $0.2 \mathrm{mg} \mathrm{S-GnRHa),} \mathrm{were}$ used for induced breeding purposes (Table 3 ).

Ahmed $^{8}$ stated that PG influenced the spawning of Labeo rohita. Atz \& Pickford ${ }^{9}$ and Chaudhuri ${ }^{10}$ have discussed various aspects of the fish pituitary gland and its role in modern aquaculture (Figure 2). From the investigational study, it was observed that the fish breed well under artificial conditions when the appropriate doses of hormonal injections were applied. Alikunhi et al. ${ }^{11}$ Haque, ${ }^{12}$ Mahanta et al. ${ }^{13}$ Alam \& Bhuiyan ${ }^{14}$ and Bhuiyan \& Aktar $^{15}$ corroborate the doses of hormones under the present study.

\begin{tabular}{|c|c|c|c|c|}
\hline \multirow[t]{2}{*}{ Species } & \multirow{2}{*}{ Sex } & \multicolumn{3}{|c|}{ Ovupin $₫$ dose / Body weight (ml/kg) } \\
\hline & & Minimum & Maximum & Mean \pm SD \\
\hline \multirow{2}{*}{ Rui, catla, mrigel, Calibaush, bata, Gonia and raj puti } & Male & 0.1 & 0.3 & $0.2 \pm 0.14$ \\
\hline & Female & 0.3 & 0.5 & $0.4 \pm 0.14$ \\
\hline Silver carp, bighead carp, grass carp, common carp, & Male & 0.2 & 0.4 & $0.3 \pm 0.14$ \\
\hline black carp, Thai pangus, Shing and Magur & Female & 0.5 & 0.9 & $0.7 \pm 0.28$ \\
\hline
\end{tabular}

Table 2 Species wise brood stock selection (length, age, weight and stocking density)

\begin{tabular}{|c|c|c|c|c|c|c|c|c|c|c|c|c|c|}
\hline & \multirow[t]{2}{*}{ Species } & \multicolumn{3}{|c|}{ Length (cm) } & \multicolumn{3}{|c|}{ Age (year) } & \multicolumn{3}{|c|}{ Weight (kg) } & \multicolumn{3}{|c|}{ Stocking Density (UNIT??) } \\
\hline \multirow{7}{*}{$\begin{array}{l}\text { Native } \\
\text { Species }\end{array}$} & & Min. & Max. & Mean \pm SD & Min. & Max. & Mean \pm SD & Min. & Max. & Mean \pm SD & Min. & Max. & Mean \pm SD \\
\hline & Rui (Labeo rohita) & 45.5 & 76 & $60.75 \pm 21.57$ & 2 & 3 & $2.50 \pm 0.71$ & 2 & 8 & $5.00 \pm 4.24$ & 25 & 35 & $30.0 \pm 7.07$ \\
\hline & Catla (Catla catla) & 64 & 88.5 & $76.25 \pm 17.32$ & 3 & 5 & $4.00 \pm I .4 \mid$ & 3 & 15 & $9.00 \pm 8.49$ & 8 & 20 & $14.0 \pm 8.49$ \\
\hline & Mrigel (Cirrhinus cirrhosus) & 45.5 & 76 & $60.75 \pm 21.57$ & 2 & 3 & $2.50 \pm 0.71$ & 2 & 8 & $5.00 \pm 4.24$ & 15 & 25 & $20.0 \pm 7.07$ \\
\hline & Calibaush (Labeo calbasu) & 30.5 & 50.8 & $40.65 \pm 14.35$ & 2 & 3 & $2.50 \pm 0.71$ & 2 & 5 & $3.50 \pm 2.12$ & 4 & 5 & $4.5 \pm 0.71$ \\
\hline & Bata (Labeo bata) & 17.5 & 22.5 & $20 \pm 3.530$ & I & 2 & $1.50 \pm 0.71$ & 0.4 & I & $0.70 \pm 0.42$ & 8 & 25 & $16.5 \pm 12.02$ \\
\hline & Gonia (Labeo gonius) & 45.5 & 96.5 & $71 \pm 36.06$ & 1.5 & 3 & $2.25 \pm 1.06$ & 1.5 & 10 & $5.75 \pm 6.01$ & 4 & 5 & $4.5 \pm 0.71$ \\
\hline \multirow[t]{2}{*}{ Cat Fish } & Shing (Heteronopneustes fossilis) & 15 & 20 & $17.5 \pm 3.54$ & I & 2 & $|.50 \pm 0.7|$ & 0.15 & 0.2 & $0.18 \pm 0.04$ & 25 & 50 & $37.5 \pm 17.68$ \\
\hline & Magur (Clarius batrachus) & 15 & 20 & $17.5 \pm 3.54$ & I & 2 & $|.50 \pm 0.7|$ & 0.15 & 0.2 & $0.18 \pm 0.04$ & 25 & 50 & $37.5 \pm 17.68$ \\
\hline \multirow{7}{*}{$\begin{array}{l}\text { Exotic } \\
\text { Species }\end{array}$} & Silver Carp (Hypopthalmicthys molitrix) & 45.5 & 82 & $63.75 \pm 25.81$ & 2 & 3 & $2.50 \pm 0.71$ & 2 & 8 & $5.00 \pm 4.24$ & 14 & 25 & $19.5 \pm 7.78$ \\
\hline & Bighead Carp (Aristichthys nobilis) & 50.5 & 100 & $75.25 \pm 35.00$ & 2 & 3 & $2.50 \pm 0.71$ & 2 & 8 & $5.00 \pm 4.24$ & 5 & 8 & $6.5 \pm 2.12$ \\
\hline & Grass Carp (Ctenopharyngodon idella) & 50.5 & 89 & $69.75 \pm 27.22$ & 3 & 4 & $3.50 \pm 0.71$ & 3 & 4 & $3.50 \pm 0.71$ & 5 & 10 & $7.5 \pm 3.54$ \\
\hline & Common Carp, (Cyprinus carpio) & 40.5 & 63.5 & $52 \pm 16.26$ & 3 & 4 & $3.50 \pm 0.71$ & 3 & 4 & $3.50 \pm 0.71$ & 5 & 15 & $10 \pm 7.07$ \\
\hline & Black Carp (Mylopharyngodon piceum) & 45 & 120 & $82.5 \pm 53.03$ & 2 & 3 & $2.50 \pm 0.71$ & 2 & 10 & $6.00 \pm 5.66$ & 3 & 4 & $3.5 \pm 0.71$ \\
\hline & Thai Pangus (Pangasius sutchi) & 43.5 & 96.5 & $70 \pm 37.48$ & I & 2 & $|.50 \pm 0.7|$ & 1.5 & 12 & $6.75 \pm 7.42$ & 5 & 10 & $7.5 \pm 3.54$ \\
\hline & $\begin{array}{l}\text { Thai Puti or Raj Puti (Barbonymus } \\
\text { gonionotus) }\end{array}$ & 20.5 & 30.5 & $25.5 \pm 7.07$ & 1 & 2 & $1.50 \pm 0.7 \mid$ & 0.5 & 1.5 & $1.00 \pm 0.71$ & 5 & 10 & $7.5 \pm 3.54$ \\
\hline
\end{tabular}


Table 3 Doses of PG and HCG for the induced breeding of the fish

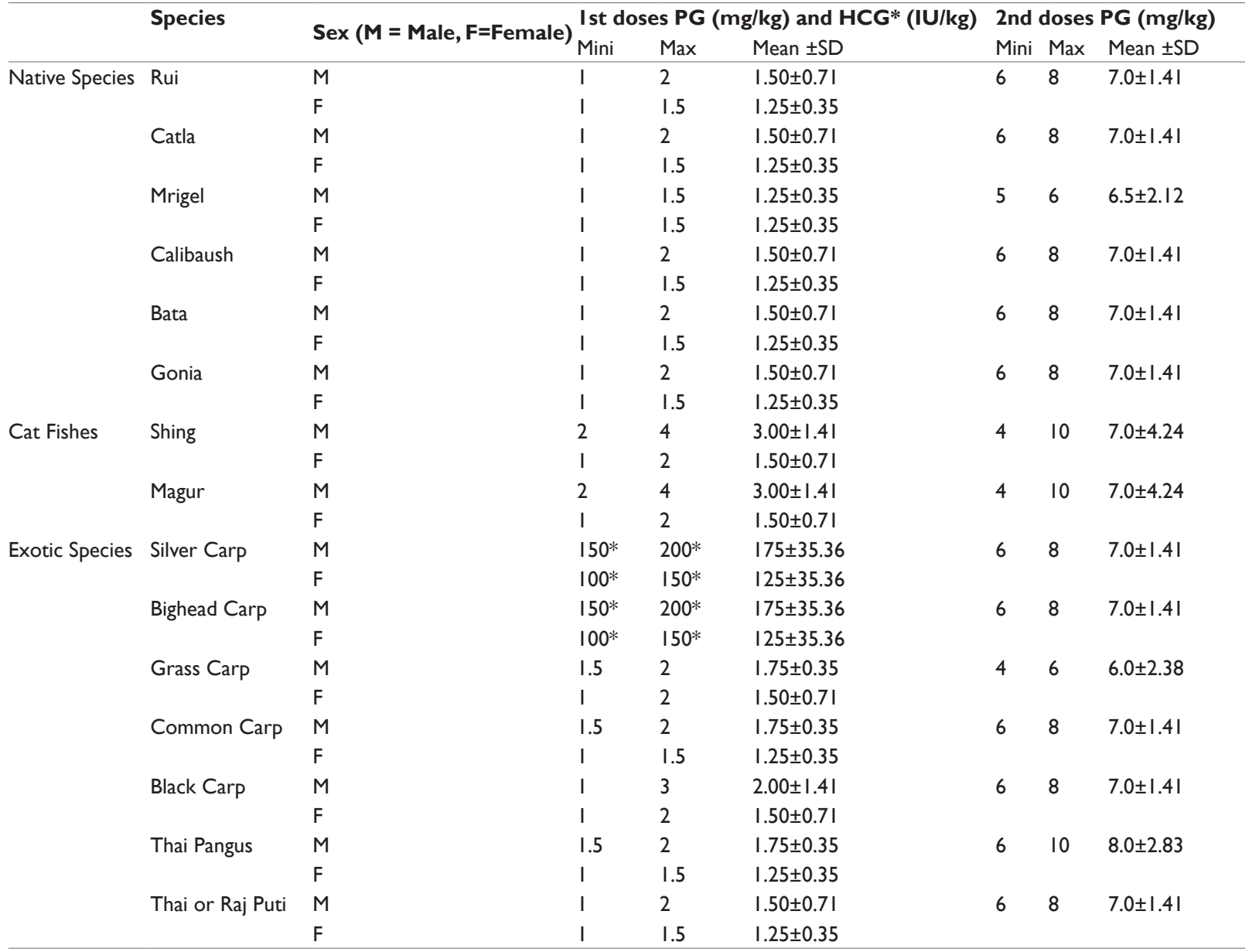

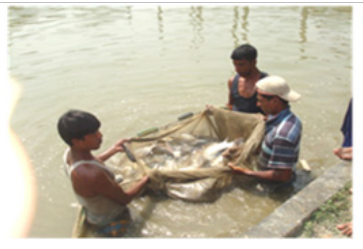

Brood fish in net

Egg collection of silver carp

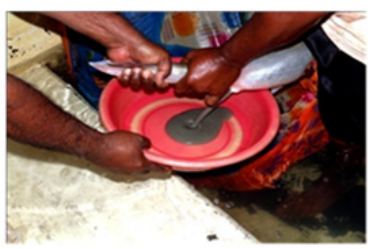

Injection method applied in silver carp

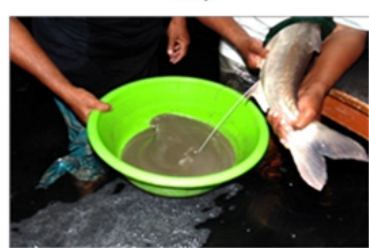

Milt collection of silver carp

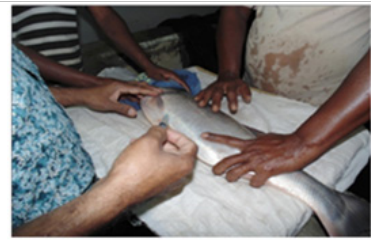

Figure 2 Pictures of induced breeding techniques in Asian modern aquaculture.

\section{Incubation and hatching}

During the survey, it was recorded that the incubation period of different fish species ranged from a minimum of 10 to maximum of 70 hours and the fish hatching rate in different hatcheries ranged from $50 \%$ to $85 \%$ (Figure 3). Singh et al. ${ }^{16}$ found that the hatching rate of Labeo rohita ranged between $90-95 \%$.

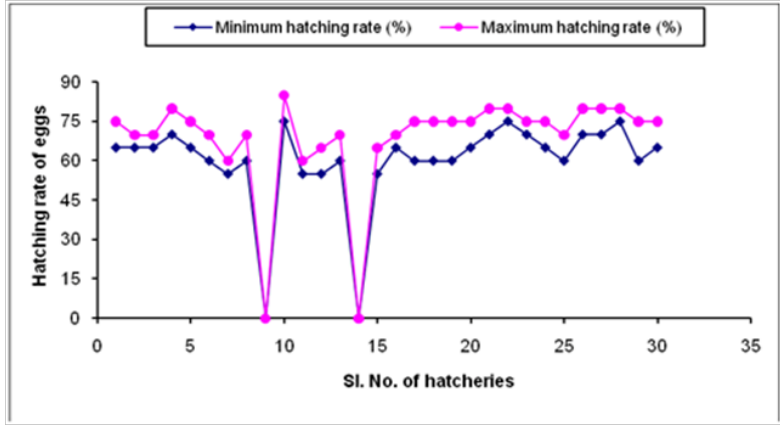

Figure 3 Hatching rates in the surveyed hatcheries.

\section{Conclusion}

From the investigational study on the survey of the fish hatcheries in the north-western region of Bangladesh, it was observed that fish hatcheries contribute to a remarkable part of inland fish production as well as to the aquaculture development of Bangladesh. This study also indicates the necessity of seed production by the induced breeding process or hypophysation. In the fisheries sector, induced breeding has opened the door of a new era throughout the world. For high quality and high quantity of fish production, it is important to give financial as well as logistic support, to share knowledge, and to organize workshops and seminars conducted by $\mathrm{DoF}^{17}$ and Universities. 
It is also necessary to develop hatchery facilities which include induced breeding techniques for the development of aquaculture in Bangladesh.

\section{Acknowledgments}

None.

\section{Conflicts of interest}

None.

\section{References}

1. FAO. The state of world fisheries and aquaculture. Food and Agriculture Organization, Rome, Italy. 2014.

2. Crespi V, Coche A. Glossary of Aquaculture. Food and Agriculture Organization of the United Nations. 2008.

3. Bhuiyan AS, Islam MK, Tanjeena Z. Induced spawning of Puntiusgonionotus (Bleeker). Bangladesh J Zoo. 2007;135(2):245249.

4. Rahman SMB, Mahmud Z, Ahmed F, et al. Induced breeding, embryonic and larval development of comet gold fish (Carassiusauratus). Electronic Journal of Biology. 2011;7(2):32-39.

5. Arantes FP, Sato Y, Sampaio EV, et al. Spawning induction and Fecundity of commercial native fish species from the San Francisco River basin, Brazil, under hatchery conditions. J Agric Sci. 2013;4:382-388.

6. Hasan MR, Ahmed GU. Issues in carp hatcheries and nurseries in Bangladesh, with special reference to health management. In: Arthur JR et al. (Eds.), Primary Aquatic Animal Health Care in Rural Small-scale Aquaculture Development. FAO Fish. Bangladesh. 2002;pp.147-164.

7. Abdus SB, Sharmin A, Naima A. Present status and fish seed production of the hatcheries of six upazilas of Rajshahi district. Univ $J$ Zool Rajshahi Univ. 2011;30:29-32.
8. Ahmed N. Factors influencing the spawning of Indian carps. Symposium of the "Factors influencing the spawning of Indian carps" Proc. Nat Inst Sci India. 1945;11(3):329.

9. AtzJ W, Pickford GE. The use of pituitary hormones in fish culture. Endeavour. 1959;18(71):125-129.

10. Chaudhuri H. Uses of hormones in induced spawning of carps. Journal of the Fisheries Research Board of Canada. 1976;33(4):940-947.

11. Alikunhi KH, Sukumaran KK, Parameswaran S, et al. Preliminary observations on commercial breeding of Indian carps under controlled temperature in the laboratory. Bull Cent Inland Fish Res Inst Barack pore. 1964;3:1-20.

12. Haque KA. Some observations on the induced spawning of major carps by pituitary hormone injection. Freshwater fisheriesResearch Station Chandpur Bulletin. 1975;1:19-33.

13. Mahanta PC, Rao KG, Pandev AK. Induced spawning of an Indian major carp, Labeorohitain the breeding season under the agro climatic conditions of Assam. J Advanced Zoology. National Bureau of Fish frenetic resources India. 1998;19(2):99-101.

14. Alam MM, Bhuiyan AS. Determination of optimum PG dose for induced spawning of Labeorohita (Hamilton 1822) Unvi J Zool Rajshahi Univ. 1999;18:103-108.

15. Bhuiyan AS, Musa ASM, Islam MK. Hatchery management in Bangladesh. Univ J Zool Raj Univ. 2008;12:20-23.

16. Singh BN, Das RC, SahuAK, et al. Balanced diet for the brood stock of Catlacatla and Labeorohita and induced breeding performance using Ovaprim. Journal of Advanced Zoology. 2000;21(2):92-97.

17. DoF. National Fish Week Compendium. Department of Fisheries Ministry of Fisheries and Livestock, Dhaka, Bangladesh. 2014;pp.144. 